\title{
Internal hernia following laparoscopic Roux-en-Y gastric by-pass: indicative factors for early repair
}

\author{
Eduardo Pachu Raia dos SANTOS', Fernando SANTA CRUZ2, Eduarda Araújo HINRICHSEN ${ }^{3}$, \\ Álvaro Antônio Bandeira FERRAZ1 and Josemberg Marins CAMPOS1
}

\begin{abstract}
Background - Internal hernia (IH) following laparoscopic Roux-en-Y gastric bypass (LRYGB) is a major complication that challenges the surgeon due to its non-specific presentation and necessity of early repair. Delayed diagnosis and surgical intervention of IH might lead to increased morbidity of patients and impairments in their quality of life. Objective - To evaluate the predictive factors for early diagnosis and surgical repair of IH after LRYGB. Methods - This study analyzed 38 patients during the postoperative period of LRYGB who presented clinical manifestations suggestive of IH after an average of 24 months following the bariatric procedure. Results - The sample consisted of 10 men and 28 women, with a mean age of 37.5 years and a mean body mass index (BMI) of $39.6 \mathrm{~kg} / \mathrm{m}^{2}$ before LRYGB. All patients presented pain, 23 presented abdominal distension, 10 had nausea and 12 were vomiting; three of them had dysphagia, three had diarrhea and one had gastro-esophageal reflux. The patients presented symptoms for an average of 15 days, varying from 3 to 50 days. Seventeen (45.9\%) patients were seen once, while the other 20 (54.1\%) went to the emergency room twice or more times. Exploratory laparoscopy was performed on all patients, being converted to laparotomy in three cases. Petersen hernia was confirmed in $22(57.9 \%)$. Petersen space was closed in all patients and the IH correction was performed in $20(52.6 \%)$ cases. The herniated loop showed signs of vascular suffering in seven patients, and two $(5.3 \%)$ had irreversible ischemia, requiring bowel resection. Conclusion - The presence of recurrent abdominal pain is one of the main indicators for the diagnosis of IH after LRYGB. Patients operated at an early stage, even with negative imaging tests for this disease, benefited from rapid and simple procedures without major complications.
\end{abstract}

HEADINGS - Bariatric surgery. Gastric bypass, adverse effects. Roux-en-Y anastomosis. Laparoscopy. Hernia.

\section{INTRODUCTION}

Even after many surgical advances regarding weight loss, the laparoscopic Roux-en-Y gastric bypass (LRYGB) continues to be one of the main treatments for obesity and its comorbidities, including cardiovascular, respiratory and metabolic conditions ${ }^{(1-3)}$. However, this procedure can lead to complications, and the development of internal hernia (IH) is an example(4). The laparoscopic bariatric technique has a lack of postsurgical adhesions as one of its main advantages. On the other hand, it can also be considered as one of the responsible factors for the occurrence of $\mathrm{IH}$ in patients submitted to this procedure(5,6).

Patients with IH post-LRYGB usually present intermittent non-specific symptoms, such as mild abdominal pain and vomiting. However, in a minority of cases when complications are already installed, a sudden onset of severe abdominal pain can manifest, requiring immediate surgical intervention ${ }^{(6)}$.

Delayed diagnosis of IH contributes to increase morbidity and mortality and the number of surgical conversions to laparotomy during the repair(7). These adverse events are caused by the development of severe complications such as ischemia, necrosis and bowel perforation ${ }^{(7)}$.
The therapeutic intervention for IH is surgical, initially being attempted laparoscopically. In most cases, a simple hernia reduction and suture of the mesenteric defect is enough. Bowel resections are only necessary in a minority of patients ${ }^{(8)}$.

Therefore, this study aimed to provide an evaluation of the indicative factors for an early diagnosis and surgical approach to repair IH post-LRYGB. We hypothesized that patients who underwent LRYGB and developed IH in the late postoperative period would present characteristic symptoms that would guide the surgical team to an early diagnosis and surgical repair.

\section{METHODS}

This is cohort study was carried out at the Hospital das Clinicas, Federal University of Pernambuco, Recife, PE, Brazil, during the period between 2015 and 2018, in which 38 patients who underwent LRYGB and had a posterior presumptive diagnosis of $\mathrm{IH}$ were assessed.

The sample was selected in accordance with the criteria of the Brazilian Society of Bariatric and Metabolic Surgery, which are BMI between 30 and $34.9 \mathrm{~kg} / \mathrm{m}^{2}$ associated with a severe comorbidity, BMI between 35 and $40 \mathrm{~kg} / \mathrm{m}^{2}$ associated with any comorbidity, or BMI $>40 \mathrm{~kg} / \mathrm{m}^{2}$ regardless of comorbidities.

The authors declare no conflicts of interest.

The authors declare no financial support.

1 Departamento de Cirurgia, Universidade Federal de Pernambuco, Recife, PE, Brasil. ${ }^{2}$ Curso de Medicina, Universidade Federal de Pernambuco, Recife, PE, Brasil. ${ }^{3}$ Curso de Medicina, Faculdade Pernambucana de Saúde, Instituto de Medicina Integral Prof. Fernando Figueira, Recife, PE, Brasil

Corresponding author: Fernando Santa Cruz. E-mail: f.santacruzoliveira@gmail.com 
This study enrolled patients who underwent laparoscopic Roux-en-Y gastric bypass and developed clinical manifestations during the postoperative period consistent with internal hernia. Those patients who had undergone bariatric surgery through other techniques, as well as those who presented a transmesenteric hernia were excluded.

All procedures performed in this study involving human participants were in accordance with the ethical standards of the institutional research committee and with the 1964 Helsinki declaration and its later amendments or comparable ethical standards. This research was approved by the Ethics Committee for Research involving human beings of the Federal University of Pernambuco, under the registration number CAAE: 02506513.1.0000.5208. All patients signed an informed consent form.

\section{Pre-surgical Evaluation}

A visual analogue scale (VAS) was used to assess pain in the studied population. Patients with severe abdominal pain after LRYGB along with the awareness of the surgeon regarding the previous suture of the peritoneal defects during the bariatric procedure were considered warning signs to emergency reoperation due to high risk of intestinal ischemia. Those patients who were suffering from mild to moderate pain were referred to perform laboratory and imaging tests such as abdominal ultrasound, $\mathrm{x}$-ray and computed tomography.

\section{Technical procedures}

After performing additional tests and deciding to proceed with the surgical approach, all patients were submitted to a diagnostic and therapeutic laparoscopy consisting of: A) closure of the Petersen space when only a hernia was identified; or B) resection of a part of the intestine with posterior closure of the Petersen space when ischemia was evidenced in the segment of the herniated intestinal loop.

\section{Statistical analysis}

The relative (percentage) and absolute $(\mathrm{N})$ frequencies of each qualitative variable were determined in order to characterize the study sample. Means and medians were used to summarize the information for the quantitative variables, and standard deviations to indicate the variability of the data. Moreover, the Fisher's Exact Test was applied to define the relationship between the surgical technique and the occurrence of $\mathrm{IH}$. All conclusions were made taking into consideration a significance level ( $P$-value) of 0.05 .

\section{RESULTS}

During the period from 2015 to 2018, 38 patients who demonstrated suggestive symptoms of $\mathrm{IH}$ were evaluated and underwent additional tests and exploratory laparoscopy to be diagnosed. Twenty-eight (73.7\%) patients were male and $10(26.3 \%)$ were female, and the mean age of the population was 37.5 years. The mean body mass index (BMI) prior to the LRYGB was $39.6 \mathrm{~kg} /$ $\mathrm{m}^{2}$ (TABLE 1).

The study findings showed a statistically significant association between the development of IH and gender, where $90 \%$ of the male population presented the pathology compared with only $46.4 \%$ of female patients.

Within the subsequent 24 months after the LRYGB procedure, the studied population demonstrated the following signs and
TABLE 1. Characteristics of the sample.

\begin{tabular}{lc}
\hline Variables & Frequency $(\mathbf{n}=38)$ \\
\hline Gender & \\
Female & $10(26.3 \%)$ \\
Male & $28(73.7 \%)$ \\
Age (years) & \\
Mean (SD) & $37.5(11.1)$ \\
BMI (Kg/m ${ }^{2}$ & \\
Before LRYGB & \\
Mean (SD) & $39.6(4.6)$ \\
At IH operation & \\
Mean (SD) & $24.8(3.3)$ \\
Presence of ring & $28(73.7 \%)$ \\
\hline
\end{tabular}

LRYGB: laparoscopy Roux-en-Y gastric bypass; SD: standard deviation; IH: internal hernia; BMI: body mass index.

symptoms: all patients in the group presented abdominal pain (usually referred as post-prandial and diffuse pain), in which 23 had abdominal distention, 10 presented nausea, 12 had vomiting, three had dysphagia, three had diarrhea and one patient presented gastroesophageal reflux (FIGURE 1).

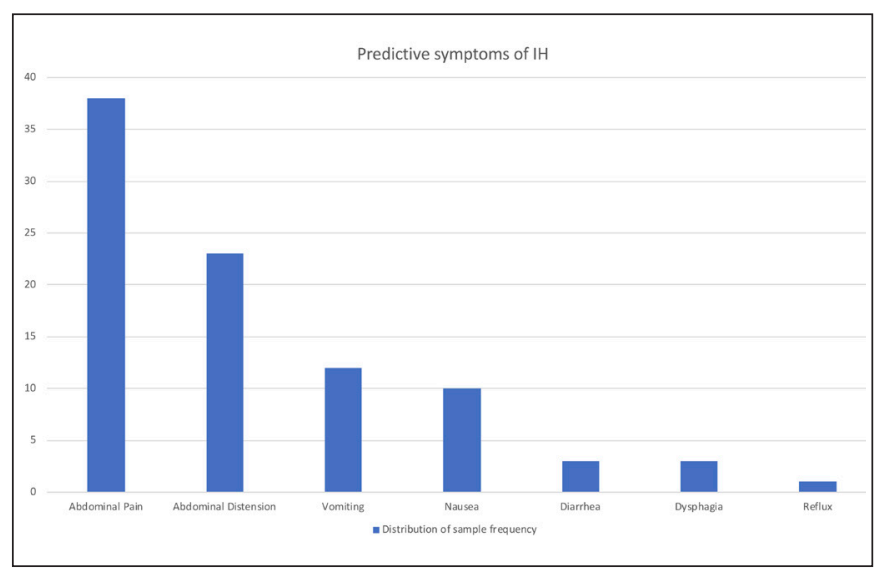

FIGURE 1. Distribution of sample frequency according to the presentation of signals and predictive symptoms of internal hernia $(\mathrm{IH})$.

The exploratory laparoscopy was initially performed on all patients, requiring laparotomy conversion in $7.9 \%$ of the cases. Petersen hernia was identified in 22 patients, while vascular suffering of the herniated bowel loop was confirmed in seven cases, while two patients among all had irreversible ischemia, requiring a resection of the damaged area. The rest of the sample presented intraoperative evidence of small intestine loop distension alone, probably due to a transient herniation, spontaneously reduced.

Hernia correction with no need of intestine resection was performed on $20(52.6 \%)$ patients (TABLE 2). All of the patients underwent closure of the Petersen space and had a surgical mean time of 45 minutes. There were no cases of complications after the surgery, and all patients presented an uneventful postoperative course.

The median follow-up time after LRYGB was 15 months, while the median time until the development of symptoms was 15 days (TABLE 3). Seventeen $(45.9 \%$ ) patients presented at the emergency department once, while the others $20(54.1 \%)$ went to the emergency department at least two times. 
TABLE 2. Surgical findings in patients who had suggestive signs and symptoms of internal hernia.

\begin{tabular}{lc}
\hline Variables & Frequency $(\mathrm{n}=38)$ \\
\hline Findings of Petersen hernia & $16(42.1 \%)$ \\
Without internal hernia & $22(57.9 \%)$ \\
With internal hernia & \\
Clinical findings of herniated loop & $2(5.3 \%)$ \\
Irreversible ischemia & $7(18.4 \%)$ \\
Vascular suffering & \\
Surgical approach & $35(92.1 \%)$ \\
Laparoscopy & $3(7.9 \%)$ \\
Laparotomy (conversion) & \\
Performed procedure & $38(100 \%)$ \\
Closure of Petersen space & $20(52.6 \%)$ \\
Internal hernia repair & $2(5.3 \%)$ \\
Enterectomy + enteroanastomosis & \\
Duration of the procedure [minutes] & $45(32.5-120)$ \\
Median $\left(\mathrm{P}_{25}-\mathrm{P}_{75}\right)$ & \\
\hline
\end{tabular}

$\mathrm{P}_{25}:$ 25th percentile; $\mathrm{P}_{75}$ : 75th percentile.

TABLE 3. Sample frequency distribution according to the follow-up of LRYGB, time of progression of internal hernia symptoms and number of emergency department visits.

\begin{tabular}{lc}
\hline Variables & Frequency \\
\hline LRYGB post-operative time (months) & $15(11.5-30)$ \\
$\quad$ Median $\left(\mathrm{P}_{25}-\mathrm{P}_{75}\right)$ & $15(3-50)$ \\
Time of progression of internal hernia symptoms (days) \\
$\quad$ Median $\left(\mathrm{P}_{25}-\mathrm{P}_{75}\right)$ & \\
Emergency department visits & $17(45.9 \%)$ \\
Once & $20(54.1 \%)$ \\
$\geq 2$ &
\end{tabular}

* Sample of 37 patients. $\mathrm{P}_{25}: 25$ th percentile. $\mathrm{P}_{75}: 75$ th percentile.

\section{DISCUSSION}

The internal hernia is a peculiar complication of LRYGB, its incidence rate ranges from $0.2 \%$ to $8 \%$, and this variability is closely related to the chosen surgical technique ${ }^{(9,10)}$.

When compared with the laparotomy approach, the laparoscopic bariatric technique is frequently related with fewer complications (lower risk of surgical wound infection and less postoperative pain) and shorter post-surgical hospitalization time. Contrastingly, it demonstrates a higher incidence of $\mathrm{IH}^{(9,24)}$.

IH occurrence varies with the position in which the alimentary limb is placed ${ }^{(9,10)}$. When the alimentary limb is located in a retrocolic position, three mesenteric windows are created, each one in a different area: transverse mesocolon, Petersen space (between mesentery of Roux-limb and transverse mesocolon) and adjacent to the jejuno-jejunal anastomosis ${ }^{(4,11)}$. In the antecolic technique, where the alimentary limb is positioned above the transverse mesocolon, only two mesenteric defects are created: in the Petersen space and the jejuno-jejunal anastomosis ${ }^{(1)}$. Therefore, the retrocolic positioning of the alimentary limb presents higher possibilities of herniation $^{(12)}$. It is recommended that all defects created must be closed in order to minimize this complication ${ }^{(10)}$.

According to Paroz et al., IH diagnosis is a challenge, as this pathology may remain asymptomatic for a long period of time and suddenly manifest with intestinal loop strangulation, leading to ischemia and necrosis of the herniated segment ${ }^{(13)}$. IH is characterized by episodes of diffuse recurrent abdominal pain in association with nausea and vomiting in the majority of cases, which are regarded as normal complaints of the postoperative period by those unfamiliar with the universe of bariatric surgery. These findings are corroborated by Iannelli et al.(14).

The difficulty in the IH diagnosis can be correlated with its non-specific clinical presentation and the fact that patients are frequently evaluated by professionals with no expertise in bariatric surgery. Our results affirm this relationship by describing that all patients from the group were taken in emergency departments and submitted to unnecessary additional tests at least once until being finally diagnosed and treated.

The data presented are in accordance with those published by Bauman et al., in which the patients they assessed were only diagnosed after several appointments with other doctors and general surgeons, presenting at the department with additional negative tests. Some had even undergone unnecessary cholecystectomies ${ }^{(15)}$.

Delayed diagnosis may lead to major surgeries, requiring extensive intestinal resections and conversion to laparotomy due to advanced ischemia and/or technical difficulty.

There were three cases of surgical conversion from laparoscopy to laparotomy in the present study. The first case was due to the late diagnosis of $\mathrm{IH}$, since the patient lived in the countryside of Pernambuco. The patient remained hospitalized in their city of origin for 15 days before being transferred to our Center where they underwent surgical treatment, during which a long, necrotic biliopancreatic loop was identified and resection and primary anastomosis were performed.

The second patient, also from the countryside of the State, presented severe abdominal pain and vomiting, being transferred to our service after five days of hospitalization. The patient was then submitted to a laparoscopy, which was converted to open laparotomy due to a ring slippage added to an extensive intestinal loop necrosis. The third case of conversion occurred due to the delay of the surgical treatment where the loop segment was fragile and had signs of ischemia without necrosis.

According to literature, abdominal pain is the main symptom associated with IH, and it is characterized by being: post-prandial, in colic, severe, intermittent and diffuse, and may be accompanied by nausea, vomiting, intestinal distention fever and diarrhea or constipation $^{(6,16-18)}$. In view of suggestive clinical features of low intestinal obstruction, internal hernia is the most likely cause, especially if the bariatric procedure was performed laparoscopically and without closure of the Petersen space ${ }^{(19)}$.

Abdominal pain occurred in all patients in the present study, especially after food intake, followed by abdominal distention, nausea, dysphagia, diarrhea and reflux. Vomiting was an uncommon finding due to the occurrence of bowel obstruction, mainly in the biliopancreatic loop, without affecting the alimentary limb, which is in accordance with other published studies ${ }^{(6,9,17,18)}$.

Additional tests are generally not specific, which makes the IH diagnosis even more challenging. Imaging techniques have a greater diagnostic accuracy when performed during the pain episode, enabling identification of the herniated intestinal loop ${ }^{(11,13,19)}$. Merely indirect signs of intestinal obstruction are shown on radiological tests in most cases, and the diagnosis is only confirmed during surgical exploration. 
Normal computed tomography findings, even with contrast in the early stages, does not rule out the possibility of IH. The highest accuracy is achieved when the intestinal loops are already at an advanced stage of ischemia. According to analyzed articles, computed tomography was effective in $69 \%$ of $\mathrm{IH}$ cases, while radiography was positive in only $45 \%(17,20,21)$.

Ultrasonography was negative in almost all cases, as well as upper digestive endoscopy. The diagnostic laparoscopy was performed in all patients, in which only two of them were negative ${ }^{(15,22)}$. From these data it is possible to infer the fragility of the complementary tests, thereby making it difficult to diagnose $\mathrm{IH}$ when the suspicion level is not high.

Therefore, diagnostic laparoscopy is very useful in view of a suspected IH case ${ }^{(15,23)}$. Despite the invasiveness of the method when compared to other additional tests, laparoscopy has many advantages. In the present study it was observed that exploratory laparoscopy was the best complementary option among the patients who presented acute abdominal pain, since it is the only method that demonstrates both diagnostic and therapeutic potential.

Perim et al. recently proposed a method to facilitate the diagnosis of Petersen's hernia after RYGB. This method consists of the application of two metal clips in the jejunum mesentery, $10 \mathrm{~cm}$ from the duodenal jejunal angle. At abdomen x-ray, these clips can be seen, normally, to the left of the spine. If, at the x-ray images, the clips are observed to the right of the spine, and the patient presents with suggestive symptoms, the diagnosis of Petersen's hernia is confirmed. This methodology is safe - the metal clips applied to the mesentery do not offer additional risks to the patient - and effective, since it contributes to establish an early and precise diagnosis ${ }^{(25)}$.

\section{CONCLUSION}

Taking into consideration the results of the present study, it is possible to conclude that the presence of recurrent abdominal pain in patients who underwent LRYGB is one of the most important predictive factors for IH diagnosis. The authors also conclude that an evaluation by a bariatric-specialized group might provide early diagnosis and treatment, avoiding complicated surgeries and laparotomy conversion, thus exposing patients to less risks.

\section{Authors' contribution}

Study design: Ferraz AAB, and Campos JM. Drafting the manuscript: Santos EPR, Santa Cruz F, Hinrichsen EA. Statistical analyses and interpretation: Santos EPR, Santa Cruz F and EAH. Data acquisition and critical revision of the manuscript: Santos EPR, Santa Cruz F, Hinrichsen EA, Ferraz AAB, Campos JM.

\section{Orcid}

Eduardo Pachu Raia dos Santos. Orcid: 0000-0003-0546-4907. Fernando Santa Cruz. Orcid: 0000-0002-3178-1036.

Eduarda Araújo Hinrichsen. Orcid: 0000-0003-2040-0549.

Álvaro Antônio Bandeira Ferraz. Orcid: 0000-0002-7290-571X. Josemberg Marins Campos. Orcid: 0000-0003-4808-0102.

Santos EPR, Santa Cruz F, Hinrichsen EA, Ferraz AAB, Campos JM. Hérnia interna após bypass gástrico em Y de Roux laparoscópico: fatores indicativos para um reparo precoce. Arq Gastroenterol. 2019;56(2):160-4.

RESUMO - Contexto - Hérnia interna (HI) após bypass gástrico em Y de Roux laparoscópico (BGYRL) é uma complicação importante que desafia o cirurgião devido à sua apresentação inespecífica e necessidade de reparo precoce. Um diagnóstico e intervenção cirúrgica tardios para HI pode levar a um aumento na morbidade dos pacientes e trazer grandes prejuízos para a qualidade de vida destes. Objetivo - Avaliar os fatores preditivos para um diagnóstico e reparo cirúrgico precoces de HI após BGYRL. Métodos - Este estudo analisou 38 pacientes durante o período pós-operatório de BGYRL que apresentaram manifestações clínicas sugestivas de HI após um período de, aproximadamente, 24 meses do procedimento bariátrico. Resultados - A amostra foi composta por 10 homens e 28 mulheres, com idade média de 37,5 anos e IMC médio de 39,6 Kg/m² antes do BGYRL. Todos os pacientes apresentaram dor abdominal, 23 apresentaram distensão abdominal, 10 tiveram náusea e 12 apresentaram vômitos; três apresentaram disfagia, três tiveram diarreia e um apresentou refluxo gastresofágico. Os pacientes apresentaram sintomas por um período médio de 15 dias, variando de 3 a 50 dias. Dezessete $(45,9 \%)$ pacientes foram atendidos apenas uma vez, enquanto os outros $20(54,1 \%)$ foram ao setor de emergência duas ou mais vezes. Laparoscopia exploratória foi realizada em todos os pacientes, havendo conversão para laparotomia em apenas três casos. Hérnia de Petersen foi confirmada em 22 (57,9\%) casos. O espaço de Petersen foi fechado em todos os pacientes, e a correção de HI foi realizada em 20 (52,6\%) casos. As alças intestinais herniadas mostraram sinais de sofrimento vascular em sete pacientes, e dois (5,3\%) apresentaram isquemia irreversível, necessitando de ressecção intestinal. Conclusão - A presença de dor abdominal recorrente é um dos principais indicadores para o diagnóstico de HI após BGYRL. Pacientes operados em estágios precoces, mesmo quando os exames de imagem se apresentam negativos, se beneficiam de procedimentos rápidos e simples, sem grandes complicações.

DESCRITORES - Cirurgia bariátrica. Derivação gástrica, efeitos adversos. Anastomose em-Y de Roux. Laparoscopia. Hérnia. 


\section{REFERENCES}

1. Sjöstrom CD, Lissner L, Wedel H, Sjöstrom L. Reduction in incidence of diabetes, hypertension and lipid disturbances after intentional weight loss induced by bariatric surgery: The SOS Inter-vention Study. Obes Res. 1999;7:477-84.

2. Remígio MI, Santa Cruz F, Ferraz Á, Remígio MC, Parente G, Nascimento I, et al. The Impact of Bariatric Surgery on Cardiopulmonary Function: Analyzing VO2 Recovery Kinetics. Obes Surg. 2018;28:4039-44.

3. Kirkil C, Aygen E, Korkmaz MF, Bozan MB. Quality of life after laparoscopic sleeve gastrectomy using baros system. ABCD, Arq. Bras. Cir. Dig. 2018;31:e1385.

4. NandipatI KC, Lin E, Husain F, Srinivasan J, Sweeney JF, Davis SS. Counterclockwise rotation of Roux-En-Y limb significantly reduces internal herniation in laparoscopic Roux-En-Y gastric bypass (LRYGB). J Gastrointest Surg. 2012;16:675-81.

5. Banka G, Woodard G, Hernandez-Boussard T, Morton JM. Laparoscopic vs Open gastric by-pass surgery differences in patient demographics, safety, and Outcomes. Arch Surg. 2012;147:550-6.

6. Garza E Jr, Kuhn J, Arnold D, Nicholson W, Reddy S, McCarty T. Internal hernias after laparo-scopic Roux-en-Y gastric bypass. Am J Surg. 2004;188:796-800.

7. Comeau E, Gagner M, Inabnet WB, Herron DM, Quinn TM, Pomp A. Symptomatic internal hernias after laparoscopic bariatric surgery. Surg Endosc. 2005;19:34-9.

8. Iannelli A, Facchiano E, Gugenheim J. Internal hernia after laparoscopic rouxen-y gastric by-pass for morbid obesity. Obes Surg. 2006;16:1265-71.

9. Cho M, Pinto D, Carrodeguas L, Lascano C, Soto F, Whipple O, et al. Frequency and management of internal hernias after laparoscopic antecolic antegastric Roux-en-Y gastric bypass with-out division of the small bowel mesentery or closure of mesenteric defects: review of 1400 con-secutive cases. Surg Obes Relat Dis. 2006;2:87-91.

10. Rodriguez A, Mosti M, Sierra M, Pérez-Johnson R, Flores S, Dominguez G, et al. Small bowel obstruction after antecolic and antegastric laparoscopic Roux-en-Y gastric bypass: could the in-cidence be reduced? Obes Surg. 2010;20:1380-4.

11. Quebbemann BB, Dallal RM. The orientation of the antecolic Roux limb markedly affects the incidence of internal hernias after laparoscopic gastric bypass. Obes Surg. 2005; 15:766-70.

12. Müller MK, Guber J, Wildi S, Guber I, Clavien PA, Weber M. Three-year follow-up study of retrocolic versus antecolic laparoscopic Roux-en-Y gastric bypass. Obes Surg. 2007;17:889-93.
13. Paroz A, Calmes JM, Giusti V, Suter M. Internal hernia after laparoscopic Roux-en-Y gastric bypass for morbid obesity: A continuous challenge in bariatric surgery. Obes Surg. 2006;16:1482-87.

14. Iannelli A, Buratti MS, Novellas S, Dahman M, Amor IB, Sejor E, et al. Internal hernia as a complication of laparoscopic Roux-en-Y gastric bypass. Obes Surg. 2007; 17:1283-6.

15. Bauman RW, Pirrello JR. Internal hernia at Petersen's space after laparoscopic Roux-en-Y gas-tric bypass: $6.2 \%$ incidence without closure-a single surgeon series of 1047 cases. Surg Obes Relat Dis. 2009;5:565-70.

16. Filip JE, Mattar SG, Bowers SP. Internal hernia formation after laparoscopic Roux-en-Y gastric bypass for morbid obesity. Am Surg. 2002;68:640-3.

17. Onopchenko A. Radiological diagnosis of internal hernia after Roux-en-Y gastric bypass. Obes Surg. 2005;15:606-11.

18. Lockhart ME, Tessler FN, Canon CL, Smith JK, Larrison MC, Fineberg NS, et al. Internal her-nia after gastric bypass: sensitivity and specificity of seven CT signs with surgical correlation and controls. AJR Am J Roentgenol. 2007;188:745-50.

19. De Bakker JK, van Namen YW, Bruin SC, Brauw LM. Gastric bypass and abdominal pain: think of Petersen hernia. JSLS. 2012;16:311-3.

20. Reddy SA, Yang C, McGinnis LA, Seggerman RE, Garza E, Kenneth L. Diagnosis of trans-mesocolic internal hernia as a complication of retrocolic gastric bypass: CT imaging criteria. AJR Am J Roentgenol. 2007;189:52-5.

21. Ahmed ARG, Rickards, Johnson J, Boss T, O'Malley W. Radiological findings in symptomatic internal hernias after laparoscopic gastric bypass. Obes Surg. 2009; 19:1530-5.

22. Papasavas PK, O’Mara MS, Quinlin RF, Maurer J, Caushai PF, Gagné DJ. Laparoscopic re-operation for early complications of laparoscopic gastric bypass. Obes Surg. 2002;12:559-63.

23. Abasbassi M, Pottel H, Deylgat B, Vansteenkiste F, Van Rooy F, Devriendt D, et al. Small bowel obstruction after antecolic antegastric laparoscopic Roux-en-Y gastric bypass without di-vision of small bowel mesentery: a single-centre, 7-year review. Obes Surg. 2011;21:1822-7.

24. Schneider C, Cobb W, Scott J, Carbonell A, Myers K, Bour E. Rapid excess weight loss following laparoscopic gastric bypass leads to increased risk of internal hernia Surg Endosc. 2011;25:1594-8.

25. Perim CA, Guedes MAE, Carvalho MFC, Lopes PGF, Simões RL. A simple method for the diagnosis of Petersen's hernia compromising the biliopancreatic limb. ABCD, Arq. Bras. Cir. Dig. 2019;32:e1429. 